more moisture, are measures of prevention; but, in extenive and thinly inhabited districts, these measures are bejond the porver of individuals or communities. In such cincumstances, there is safety only by removal beyond the circle of the miasm, especially at those seasons when it is lnown chiefly to abound. If this also cannot be accomplished, then the strictest attention to any deviation from health, the avoidance of intemperance and of exposure to night air, and the selection, as sleeping apartments, of the uppermost rooms of the house, are the most approved precautions.

3. In cities and torons the congregation of human beings, and the habits of the people thence arising, are prolitic sources of sickness and mortality. These, for the most part, are under control, or within our reach; and here an extensive field is open for individual and united exertion.

Where PUBUIC BATHS AND W ASHBOUSES are established, with every requisite convenience, at very moderate fixed charges, there can be no excuse for personal uncleanliness. To all persons, especially to those of the labouring classes and their children, a tepid bath once or twice in the week must do good. It may be safely and strongly recommended, not only for the comfort of a clean skin, but in a precautionary and hygienic point of view; and those families whose abodes are confined for space may be assured that the slight additional trouble, entailed by the use of the public washing department, will be amply repaid by the health, vigour, and increased comfort of themselves and their children. Life is so greatly under the dominion of external agencies-air, temperature, light food, and water, that health and strength of constitution may be practically regarded as exponents of the care and attention paid to them. Moreover, sanitary inquiries have most clearly demonstrated that it is in correcting any neglect of these outward agencies, that our control over epidemical diseases is most manifest. Therefore, to the authorities of a town, the prevention and removal of nuisances, cleansing of noisome courts and alleys, supervision of common lodginghouses, sewerage, and the supply of wholesome water, legally appertain; but personal care of health, especially that of children, proper clothing, avoidance of unwholesome food, cleanliness of person, and the thorough ventilation of rooms and houses, must devolve on individuals. Refuse-heaps, dust-bins, pigsties, yards with stagnant pools of water, and all offensive accumulations, seeing how greatly their effluvia are known to contribute to epidemical diseases, ought in common justice to neighbours and the community to have the constant attention of their owners; and if decaying refuse matters of any kind be permitted to accumulate unnecessarily, the Legislature has wisely empowered a properly appointed inspector to step in and enforce the performance of a neglected duty.

It may appear to some readers trite and commonplace to dwell as we have done on precautionary measures, on the one hand, to be commended; or on their opposites, impure air, crowded apartments, inebriation, unwholesome food, and dirty habits, to be avoided; but let it be remembered that cholera has already been visiting its wonted haunts, singling out its victims from the predisposed class; and, judging of the future progress of its present visitation by the past, we may expect in the coming year (1854), to witness a severe, and in the worst parts of towns, perhaps, a decimating attack.

An impressive lesson in hygiène, on more than one occasion, has been inculcated by an extensive fire, which, effectually dispersing the inmates of crowded dwellings, and sweeping away a mass of close courts, lanes, and alleys, has stayed the raging of an epidemic, and greatly improved the sanitary state of the town. During the summer of 1831, cholera visited with great severity the middle of Russia ; in June and July, it reached Constantinople ; but after the famous fire at Pera, in August, it entirely disappeared from that city. The fire of London, in 1666, immediately succeeded the great plague, a pestilence which carried off 100,000 persons. The city became much more hedilhy after the fire, care having been taken in rebuilding to make the streete wider and man ingular than before. "The plague," ajs Hume, "whicil used to break out twice or thrice every century, and indeed was always lurking in some corner or other of the city, has not appeared since the great fire of 1666 ."

In 1842, nearly one-third of the central part of Hamburgh was destroyed by fire, and this part of the city has been re-constructed on a plan arowedly in conformity with sanitary principles. The result was, as respects the epidemic cholera of 1849 , that, comparing the poor residing in the rebuilt part of the town with those residing in the old portion, not more than one of the former was attacked for ten of the latter.

Great calamities are seldom without an attendant good; and the facts we have narrated prove that great fires in large cities have been the means of saving a thousand-fold more lives than they have destroyed. The lesson which they teach upon the sanitary influence of dispersion and ventilation, ought not merely to make a passing impression, but to be practically enforced in all cases where new streets are added to a town.

The substitution of wide open streets for narrow damp thoroughfares, cleansing and whitewashing the abodes of the poor, dispersion of the inmates of crowded tenements, or enlargement of the space in which the people breathe and sleep, together with wholesome food and good water, have in all places been followed by a marked check to the progress of epidemical disease ; and whatever may be the source of the miasm, it cannot be doubted that that mode of conduct and living which is a safeguard against it, is equally a safeguard against the inroads of sickness and mortality in infant life.

Lastly, let it be remembered that in every town of England, amongst those who neglect the rules and precautions which have been mentioned, one-lialf of the children born die before they complete the fifth year of their age.

Maidstone, January, 1

[To be continued.]

\section{DEGENERATIONS OF THE MUCOUS MEMBRANE OF THE STOMACH.}

By C. HANDFIFLD JONFS, M.B., F.R.S., Assistant Physician to St. Mary's Hospital.

so. II.

Is a communication to the Association Jodrnal of Oct. 7, 1853 , I drew attention to the not unfrequent occurrence of degenerative changes in the mucous membrane of the stomach, instancing simple and fatty atrophy, the formation of nuclear deposits, and intertubular fibroid development. At present, I purpose to enter a little more into detail respecting these and associated morbid changes.

Nuclear masses, as I term large circumscribed formations of nuclear corpuscles, are very frequently met with in various situations. Sometimes they lie in the subtubular tissue, that thin expansion of fibrous tissue which passes off from the corium to envelope the deep blind ends of the tubes. Sometimes they are eml. Hled in the substance of the mucous membrane, in the midst of the tubes; and in this case they may be situated in its most superficial part. Often they are well defined, and the tissue in their immediate vicinity is tolerably healthy; but still more commonly they spread out on all sides, and infiltrate their substance between the adjacent tubes. When circumscribed they get easily detached from the surface of a vertical section during manipulation; and a cavity is then left, in which the tubes are manifestly wanting. In their primary state they consist of very perfect, well formed, distinct, nuclear corpuscles, just like those which fill up the cavities of the thymus: these lie heaped closely together, and there is scarce any trace of granulous matter imbedding them to be seen; in later stages, however, of their existence, oil-molecules, in varying quantity, sometimes considerable, are mingled with, or replace them. Frequent as is the occurrence of these 


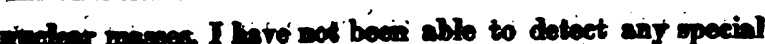
condition which seems to exert a cuscitive inflecece upon their production. Hyperwmis certainly is not often aseocinted with them, nor are there traces of past congestion. It scems as if, from some failure in the healthy assimilative pover, plasma, which should have ministered to the formafion of Bealthy epithelium within the tubes, passed into this 10N, simple, primary organic form in their interstices. They benr some resemblance to the masses which constitute the so-called solitary follicles of the intestine; but I am perswaded that they are not normal structures. In particular, I can state that they are less frequent in the stomachs of young children than in those of adults; the former, as might be expected, having generally sounder and healthier organs than the latter.

Another form of morbid alteration, evidently allied to the preceding, is extremely common. It consists in the infiltration of nuclear corpuscles, with more or less distinct fibroid stroma, among the tubes throughout the whole thickness or a part only of the mucous coat. In some specimens, this change is very marked; instead of parallel ranged vertical tubes, with distinct interspaces, the eye beholds nothing but a confused mass of nuclei, with a dim connecting medium, and débris of inrolved tubes lying here and there. In others (and this is one of the very commonest forms of change), the tubes are merely obscured; they can still be made out quite satisfactorily; but the practised eye perceives that they are much less clearly visible than in a perfectly healthy specimen. This state is often combined with the preceding. Nuclear masses are then seen lying beneath, or in the substance of, the mucous membrane, which is infiltrated all around with the same kind of material, only more diffusedly. Elongated and fibre-forming nuclei are not uncommonly to be found at the torn edge of a section. The fibroid stroma which, together with the nuclei, pervades the mucous tissue, is seldom very distinct; of its existence, however, in many cases, there can be no doubt; and it seems in the highest degree probable that the condition of complete atrophy of the tubes, and replacement of them by manifest filbroid tissue, is a further stage of the development of the same. Of this I have now seen two or three instances. Case viII, recorded in my former paper, may be regarded as another instance of the same kind, although the material replacing the tubes was rather granular and fatty than Gbroid. It is worth noticing, that even in the healthy state, there exists at the surface of the stomach, immediately beneath the line of the basement membrane, a small quantity of nucleated granular substance. The existence of this is very manifest in examining the pyloric region, where it fills up the interior of the low villi and folds which spring up between the orifices of the tubes; in the splenic and mid-regions it is less apparent, but still may be seen here, I think, in some specimens which can scarcely be considered otherwise than normal. This nucleated substance is quite similar to that which is so conspicuous in the interior of the intestinal villi, and between the openings of the Lieberkühn follicles in the large intestine, to which I gave some years ago the name of "substratum of the mucous membrane". The abnormal increase of this extratubular formation would produce nearly such a condition as that which we are now considering. In many specimens of this kind there is but little appearance of any fatty deposit; but sometimes the involved tubes, or rather their debris, are seen in a state of degeneration forming streaks of opaque fatty matter. The line of basement membrane, which in healthy stomachs is seen running along the margin of the upper border of a vertical section, is often lost; it becomes less distinct, is replaced by granulo-homogeneous substance containing elongated nuclei, and at last, in the most adranced cases, the margin becomes ragged and irregular, and may be said to be really ulcerated. This takes place, of course, all the sooner when a nuelear deposit has been formed in the superficial lajer of the mucous membrane, and is beginning to undergo a disintegrating change.

Another variety of morbid alteration, which is mot with occacionally, but according to inj experience much less firegrentily thin the foregoing, is the formation of ogule conties. Theee, as fur as I hore seen, are alraje coninected with nuclear depoeits, in the midst of which a eavity is preduced, probably by the liquefying of the particles themselres, while a well, more or less defined, is formed on the limiting surface. This viow seems to us most in accordance with the fact that the form of the cavities is generally rather irregular. In one instance, indeed, I have ceon a true spherical cyst with a well of homogeneous membrane imbedded in a nuclear mass; it was of small size, 1-66th of an inch, and may have been generated in the same way that cysts are in other parts, and not by the mere disintegration of tissue, and the consequent production of an empty space. The two cysts mentioned in Case $v$ of $\mathrm{my}$ former paper I also incline to regard as independent formations, and not mere vacuolø. Perhaps it would, therefore, be most correct to distinguish cystoid cavities from true cysts occurring in this situation. I have never seen anything which showed that distension of partially obliterated tubes was the mode of origin of the cysts. A specimen which I lately examined was very remarkable from the great number of the cystic cavities which it contained. They were almost confined to the splenic region, and appeared by direct light to the naked eye as minute dopressed spots suggesting the idea of vesicles filled with clear fluid; by transmitted light they appeared semitransparent, and it was evident, that in each of them the mucous membrane had undergone a loss of substance. The contents of these cysts were nuclear particles in small numbers tloating in a clear fluid. There was but a slight amount of vascular injection, and it was evident in this case as well as in others, that the process by which the cavities were formed was rather a peculiar derangement of the normal assimilative action, than any that could be regarded as essentially connected with inflammation. It is a question of some interest, whether such a process of liquefying of abnormal deposits as I have supposed to take place be identical with or analogous to that by which the perforating ulcer is formed. I was at first inclined to suppose that it was; but in two ulcers which I lately examined I could find no evidence that such was the case.

The mammillated condition of the mucous membrane of the stomach has been often noticed, but I doubt much whether it has hitherto been rightly interpreted. Both Andral (Précis d'Anut. Pathol., vol ii, p. 48) and Rokitansky in his great work (p. 25, vol. ii, of Sydenham Society's Translation), speak of it as the result of partial hypertrophy. The former says, "it is not rare to find the mucous membrane of the stomach hypertrophied in all its extent: sometimes, as it thickens, this membrane preserves a smooth and uniform aspect; sometimes, being unequally hypertrophied, it presents a multitude of elevations which are separated by sinuous depressions, it seems then as if mammillated." I am much inclined to doubt the existence of any condition which can truly be termed hypertiophy of the mucous tissue. Indeed, it is conceivable that when turgid with blood, or infiltrated with recent exudation, it would be thickened, but this would be no true hypertrophy; and even such a thickening as this it has not occurred to me to meet with in more than seventy examinations I have recently made. Atrophy of the tubular structure is abundantly common, but hypertrophy is certainly the reverse, unless a degree of bulging and distension of the lower parts of the tubes by fatty epithelium should be accounted as such. But with respect to the mammillated condition, we can offer the following evidence to show that it is the result of a local and partial atrophic process. If the mucous membrane be carefully dissected off from the muscular coet, and held up to the light, the track of the furrows or "sinuous depressions", as Andral terms them, which mark out and separate the mammille, are seen to be much more transparent than the intervening tissue; manifestly the mucous membrane is thinner there than elso where. This experiment also shows that the mammillution of the surface is not the result of puckering from contswetion of the muscular cost or of the submucous tisene, for the man- 
Inen doen not becoms nniform by being spread ont. Amain, if a vertical section be made, 80 as to cross one of the furrowe and include the bounding mammills, it is readily seen under the microscope that the tubes at the depressed part are materially shortened, and are far from attaining the same level as those on each side. I have studied very carefully in different specimens the cause of this local shortening, and am pretty well satisfied that it is due in most if not all cases to abnormal deposits taking place in the part affected. Thus nuclear masses or infiltrations will be seen in the site of the depression, while the tubes in the vicinity are free, or nearly so. These deposits may lie at the base of the tubes, or nearer their free surface. In some instances, where there is no other apparent alteration than the local shortening of the tubes, two hypotheses may be entertained: one, that a simple atrophy of the tissue has occurred; the other, that a nuclear mass has been formed near the surface, has disintegrated, and been thrown off, leaving the tissue sunk in where it existed. In any case, I think there can be no question that the mammillated appearance is a sign of local atrophy rather than hypertrophy; and I would ask attention to the correspondence between it and the granular condition of a degenerated kidney. In both instances the less affected part remains prominent, while the intervening atrophied part shrinks in. Mammillation has appeared to me to occur much more frequently in the middle and pyloric than in the splenic region. It is, perhaps, possible that in cases where the mammillated condition is very slight, it may depend upon some abnormal contraction of the corium of the mucous membrane; but this is clearly not the efficient cause in the more marked cases.

There is one form of change not unfrequently observed in the pyloric region, which 1 am unable to give a satisfactory account of. It consists in this, that while in the healthy condition a vertical section should present a continuous row of parallel tubes, in this case, the row is interrupted at intervals, and there is seen in place of two or more contiguous tubes a bunch of convolutions, usually filled with a fatty epithelium, and lying in the deeper part of the mucous membrane. The idea conveyed is, that from some cause the upper halves of the tubes have perished, while the lower are thrown together in the way described. The fresh case detailed in my previous paper was an extreme instance of this kind.

The state of self digestion, though it be not a change to be classed with those already described, may be briefly noticed here. In a minor degree, I think it is by no means uncommon; the mucous membrane in the splenic region is translucent than that of other regions. In extreme instances, the mucous membrane over a certain space, which may be very often found much softer, more attenuated, and more definitely limited, has completely disappeared, and the white submucous tissue is exposed with black ramifining streaks crossing it, which are vessels containing altered blood. The fluid contents of the stomach and the affected tissue react most powerfully acid, but hardly more so than the chyme which is found in the stomachs of persons who have died while digesting. A vertical section of the affected part placed under the microscope shows that the tubular tissue is reduced to a mere layer of débris, if it has not quite disappeared; the submucous tissue is altered just as it would be by the action of strong acetic acid; all the white filamentous tissue is rendered transparent; the vessels and nerves are brought out, especially their nuclei, with great distinctness; and the blood in the vessels is converted into dark yellow pigment. I quite agree with Rokitansky that this change is not merely the result of the action of the secreted gastric juice on the walls of the stomach, as I have found no trace of it in stomachs which contained abundance of acid chyme, and have found it strongly dereloped in a stomach which was empty. It seems as if a powerful acid was generated in the last hours of vitality within the tubes, which corrodes and destroys first themsolves, and afterwards the adjacent tissues.

Black pigment, as is well known, is not uncommon in the atomich. It is most often deposited, I think, in the superficial lajer just beneath the besement membrano; bet I have lately examined an extreme case of black discoloration of the mucous membrane of the stomach, where it pervaded the whole thickness of the mucous tissue in large quantity. In this case, the tubes were utterly disintograted, and their débris mingled with the black matter which existed in the form of large granules, and globules rather above the size of a mucous corpuscle. I have seen black pigment deposited within the tubes, but its common situation is between them. Sometimes opaque dark granules and masses are seen just beneath the basement line of the surface, which have, by transmitted light, all the appearance of black pigment; but, as they appear white by direct light, they are probably fatty matter. In connexion with the statement, that the superficial layer of the mucous membrane is the more usual seat of the black matter, it is worth remarking, that it is in the same situation that capillary injection is always most marked. I'he capillaries which surround the orifices of the tube are much wider than the vertical straight intertubular vessels, and seem to be the especial seat of congestion. Thus, in a stomach whose mucous membrane was of a deep red colour throughout, I found that the stress of the blood-current on these resseis had been so great, that there were numerous patches of extravasation around them; while all the other vessels, though completely filled with blood, remained unruptured. There can be no doubt that the black pigment, in most if not all cases, is the product of alterations taking place in exuded hæmatine. The dark red, manifestly hæmorrhagic spots, which are occasionally seen on the mucous surface of the stomach, are found, under the microscope, to be made up in great part of dark granules of pigment.

With regard to changes originating in the tubes themselves, I have but little to add to the statements adranced in my former paper. The lower ends of the tubes are the parts which oftenest appear atrophied; and this seems to occur partly from a special tendency, partly from their being most exposed to the compressing action of new formed fibroid tissue. When tubes thus involved, as is often the case, undergo fatty change, this is attended with shrinking and wasting; while the fatty change which befalls healthy tubes causes both enlargement of the epithelial cells and distension of the canal. A similar difference may be observed in the liver; cells imprisoned amid tracts of new formed tibroid tissue, in cirrhosis, undergo fatty degeneration; but they waste and break up into mere masses of oil drops, while the cells in simple fatty degeneration enlarge by intussusception of oil. It is of some interest to remark, that while, in most healthy stomachs, test-paper applied to the mucous surface shows a distinctly acid reaction, this is much less apparent, or wanting, in those where the tubes are much wasted. A vertical section of a healthy stomach, under moderate pressure, exhibits a large quantity of epithelium escaping from the orifices of the tubes; but very little can be forced out in this way when the tubes are extensively degencrated. In a few instances, I have seen the epithelial lining of the tubes thrown off in the form of large hollow pieces, forming tolerably complete casts of their interior. This indicates that it possesses a greater degree of stiffness and cohesion than is natural, for, in the healthy state, it always exudes as a solid unturm mass; and further, as the central canal was wider than usual, it also shows that some degree of wasting had occurred.

The accurate determination of the genesis of the above changes requires much longer investigation than the ascertaining of their existence and frequent occurrence. As far as our inquiry has at present proceeded, our original anticipation is confirmed, that they are not of inflammatory origin. I certainly have not found them more frequently in stomachs whose mucous membrane presented traces of by-past inflammation, than in those which were quite free. The isolated nuclear deposit seems to occur in every state, and, while of small amount constitutes but an insignificant deviation from health. When diffused among the tubes, and associated with fibroid formstion, I incline to the belief that they are often dependent on some such condition of 
tho genemal system as gives rise to cirrhosis of the liver and grenular disease of the kidney, but they certainly are not peculiar to this state. With regard to symptoms, it can handly be expected that there should be any special ones; loss of appetite, weak digestion, epigastric uneasiness, and emaciation, are common to functional as well as to organic diseases of the stomach; and it is rather from the general aspect and history of the case, the length of time the symptoms have existed, the facies (which the practised eye of a true observer reads so instinctively), and the tout ensemble, that the question of the existence of actual organic change must be determined. After much observation of disease of the stomach, I feel inclined to believe that serious organic disease of the mucous membrane betrays itself rather by general symptoms, as sallow aspect, failing strength, loss of flesh, and increasing debility, than by the vomiting, pain in the lower part of the chest and left side, aggravated by taking food, hypochondriasis, and hyperæsthesia, which sufferers from functional derangement only of the organ describe so piteously, and with so much hyperbole. The seriously diseased viscus seems to have become in a measure callous, and does not react with that acute sensibility which it displays when in a sounder state. The practical fact to bear in mind is, that, about and after the middle period of life, and earlier in cases of premature decay, the glandular structure of the stomach is apt to become seriously degenerated. One of the important agents in the business of nutrition is thus more or less completely put hors de combat; and though chemists tell us, and we do not doubt, that albumen and flesh can bo digested in the intestine without having been exposed to the gastric juice, and though oily and starchy matters are not digested in the stomach at all, still the physician cannot resign his conviction that the loss of a proper digestive stomach is a very grave one to the system.

Opportunities of obtaining an inspection of the bodies of persons who have suffered up to the time of death with symptoms of ordinary dyspepsia are so rare, that the author of this paper would feel it a very great kindness if any member of the profession, to whom the opportunity may occur, would forward to him the specimen for minute examination, with a short account of the sex, age, duration of illness, and cause of death. It can scarcely be doubted that morbid anatomy might yet supply further valuable information, if inquiry were especially directed to the nature of the changes which occur in common every day disorders. How desirable, for instance, it would be to know exactly the seat and the kind of the morbid action which is set up in a "bilious attack", or a "sick headache"; or to scrutinise the state of the mucous membrane in a case of irritative dyspepsia! This would be better knowledge than that of the exact course of a fracture of the skull, or the demonstration of a pericarditis or valvular cardiac disease.

1 Southwick Place, Hyde Park, London, Jan. 13th, $18 \% 4$.

\section{REPORTS OF SOCIETIES.}

\section{MEDICAL SOCIETY OF LONDON.}

SATURDAY, JANCARY $21 \mathrm{st}, 1853$.

Edwin Canton, Esq., Vice-President, in the Chair.

COLLODION IN THE TREATMENT OF ENTROPION. BY J. 3r. WLNN, Mr.D.

Dr. Wins commnnicated the case of an old lady, who had been twice operated on for entropion without success, but had been relieved by the application of collodion. He believed this treatment to be of great utility in relieving the entropion. The mode of application is to pass a brush, dipped in collodion, rapidly across the fibres of the orbicularis palpebrarum; and, if it be coloured with a little cochineal, the want of colour will not be perceived. He did not recommend it as effecting permanent cure; but it corrugates the skin, and does not increase elongation.

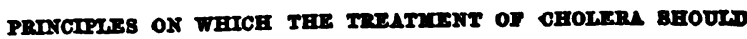
BE BASED. BY JOHN SNOW, K.D.

In the greater number of epidemic or self-propagating diseases, the morbid poison enters the blood in some manner, and multiplies itself in that fluid during the period of so called incubation. But cholera seems to constitute one of the exceptions to this rule; for, instead of commencing with fever or other general symptoms, it begins with an effusion into the allmentary canal, and the symptoms which follow are the result of this effusion. The analyses of the blood in cholera patients, performed by Drs. Garrod and Parkes, show that its thick and tarry looking condition arises from the loss of its watery part by the purging and vomiting; the function of absorption being also suspended. The effusion into the stomach and bowels is always sufficient to reduce the blood to the condition in which it is found in cholera; and the reason why the purging and vomiting are sometimes more copious in the milder and more protracted cases than in those which are rapidly fatal, is that, in the former cases, absorption still takes place. The inability of the thick and tenacious blood to pass through the pulmonary capillaries, except with great difficulty and in very small quantity, is the cnuse of the distressing feeling of want of breath, and also of the empty state of the arterial system, and the consequent faintness, coldness, and other symptoms of collapse. 'The temporary removal of the symptoms of cholera by a weak saline solution, which merely replaces the lost part of the blood, shows that these symptoms are not due to any cholera poison circulating in the blood. The circumstance, that the disease can be stopped or prevented in those cases which commence gradually, by the ordinary remedies for diarrhwa, also proves the same point; for it cannot be supposed that such medicines could have any effect on a poison circulating in the blood.

This view of the pathology of cholcra is confirmed by the evidence which shows that the materies morbi of the disease enters the alimentary canal by being accidentally swallowed, and there multiplies itself. It abstracts the watery part of the blood, either by setting up irritation in the mucous membrane, or by a power analogous to that by which the epithelial cells of the various organs abstract the different secretions in the healthy body.

The principles of treatment suggested by this view of the pathology of cholera ure, to give such medicines as have the power of destroying low forms of organised beings, and of preventing putrefaction, fermentation, and other kinds of molecular change in organic matter, as these agents would be most likely to destroy the cholera poison, or counteract its effects. The remedies should be given in such quantities and in such a form as to insure their application as much as possible to the whole surface of the alimentary canal, and should be continued until there is no fear of collapse. Prepared animal charcoal, sulphur, and creasote, are among the remedies which seem to deserve further trial. The administration of cold water in the stage of collapse is in accordance with both reason and experience; while all attempts to bring the patieut out of this stage by stimulants and the application of heat, are cqually opposed to both.

\section{NORTH LONDON MEDICAL SOCIETY. \\ WedNeSdaY, JaNuary 11Th, 1854. \\ R. Quarx, Esq., F.R.S., President, in the Chair.}

The officers for the ensuing year were nominated. The elections will take place on February 8 th.

REVTVAL OF THE ANCIENT TREATMENT OF CALLOUS ULCERS BY EXCISION OF THE MARGIN. BY JOHN HAINWORTH, ESQ

After reviewing the numerous instances in which modes of treatment and instruments in vogue amongst the ancients have, in our own time, been revived with advantage, Mr. HaINworTh in sideration other ulcers depending upon varicose veins, and their local or general causes. 'The ulcer in question was apparently sunken, oval or circular, having a livid, pale red, and glassy surface, which was void of granulations, and excreted a thin scanty unirritating fluid. The sore had a hard precipitous white or dusky edge, surrounded by integument, thickened and indurated by infiltration. The ulcer was, however, not sunken, but only apparently so from the elevation of its margin; and therefore Mr. Hainworth questioned the propriety of assigning to it the name of "deep and excavated ulcer", as done by Mr. Stafford. In reviewing Mr. Syme's and Mr. Critchett's descriptions, he admitted that considerable thickening by effusion ex- 